\title{
Epigenetic considerations in aquaculture
}

\author{
Mackenzie Gavery $^{1}$ ， Steven Roberts ${ }^{\text {Corresp. } 1}$ \\ ${ }^{1}$ School of Aquatic \& Fishery Sciences, University of Washington \\ Corresponding Author: Steven Roberts \\ Email address: sr320@u.washington.edu
}

Epigenetics has attracted considerable attention with respect to its potential value in many areas of agricultural production, particularly under conditions where the environment can be manipulated or natural variation exists. Here we introduce key concepts and definitions of epigenetic mechanisms, including DNA methylation, histone modifications and noncoding RNA, review the current understanding of epigenetics in both fish and shellfish, and propose key areas of aquaculture where epigenetics could be applied. The first key area is environmental manipulation, where the intention is to induce an 'epigenetic memory' either within or between generations to produce a desired phenotype. The second key area is epigenetic selection, which, alone or combined with genetic selection, may increase the reliability of producing animals with desired phenotypes. Based on aspects of life history and husbandry practices in aquaculture species, the application of epigenetic knowledge could significantly affect the productivity and sustainability of aquaculture practices. Conversely, clarifying the role of epigenetic mechanisms in aquaculture species may upend traditional assumptions about selection practices. Ultimately, there are still many unanswered questions regarding how epigenetic mechanisms might be leveraged in aquaculture. 


\section{Epigenetic considerations in aquaculture}

2 Mackenzie Gavery, Steven Roberts*

3 School of Aquatic and Fishery Sciences, University of Washington. Seattle, WA, USA

4

5

6 "Corresponding Author:

7 Steven B. Roberts

81122 NE Boat St., Seattle, WA, 98122, USA

9 Email address: $\underline{\text { sr320@uw.edu }}$

10 


\section{Abstract:}

12 Epigenetics has attracted considerable attention with respect to its potential value in many 13 areas of agricultural production, particularly under conditions where the environment can 14 be manipulated or natural variation exists. Here we introduce key concepts and definitions 15 of epigenetic mechanisms, including DNA methylation, histone modifications and non16 coding RNA, review the current understanding of epigenetics in both fish and shellfish, and 17 propose key areas of aquaculture where epigenetics could be applied. The first key area is 18 environmental manipulation, where the intention is to induce an 'epigenetic memory' either 19 within or between generations to produce a desired phenotype. The second key area is 20 epigenetic selection, which, alone or combined with genetic selection, may increase the 21 reliability of producing animals with desired phenotypes. Based on aspects of life history 22 and husbandry practices in aquaculture species, the application of epigenetic knowledge 23 could significantly affect the productivity and sustainability of aquaculture practices.

24 Conversely, clarifying the role of epigenetic mechanisms in aquaculture species may upend 25 traditional assumptions about selection practices. Ultimately, there are still many 26 unanswered questions regarding how epigenetic mechanisms might be leveraged in 27 aquaculture.

\section{Introduction}

Maintaining and improving aquaculture production requires an understanding of genetic and physiological mechanisms that control desired traits. Elucidation of these mechanisms has led to the development of pioneering biotechnological methods that have important applications. For example, molecular markers are used in broodstock selection and transcriptomic studies have been used to improve environmental conditions to decrease physiological stress in animals. Recently, interest in epigenetics within the agricultural community has surged as it has become more clear that epigenetic mechanisms can provide a measurable link between environment and phenotype. 
41 mechanisms (or 'marks'), including DNA methylation, histone modifications and non-coding

42 RNA activity, influence gene expression primarily through the local modification of

43 chromatin. Unlike DNA, epigenetic marks can be directly influenced by the environment,

44 and therefore have been shown to be important mediators of phenotypic responses to

45 environmental signals (Figure 1). For example, in mammals, nutrition (Weaver et al., 2004),

46 exposure to toxins (Dolinoy et al., 2006), and photoperiod (Azzi et al., 2014) have all been

47 associated with changes in DNA methylation and concomitant changes in phenotype. DNA

48 methylation patterns in fish show a similar sensitivity to the environment (Wang et al.,

49 2009; Strömqvist, Tooke \& Brunström, 2010; Campos et al., 2013; Artemov et al., 2017).

50 While many environmentally-induced epigenetic changes are transient, some may persist

51 over the course of an organism's lifetime (Weaver et al., 2004; Dolinoy et al., 2006; Heijmans

52 et al., 2008). Evidence of transgenerationally-inherited epigenetic changes has been

53 reported in vertebrates (Guerrero-Bosagna et al., 2010; Manikkam et al., 2012; Rodgers et

54 al., 2015; Knecht et al., 2017), invertebrates (Rechavi et al., 2014; Klosin et al., 2017) and

55 plants (Hauser et al., 2011). Thus, it is important to understand the nature and function of

56 these mechanisms and their influence on phenotype in fish and shellfish.

Interest in epigenetics has been gaining ground in agricultural science for crops

58 (Ong-Abdullah et al., 2015; Álvarez-Venegas \& De-la-Peña, 2016) and, more recently,

59 livestock (Goddard \& Whitelaw, 2014; González-Recio, Toro \& Bach, 2015), but less is

60 known about epigenetic mechanisms in economically valuable aquaculture species. Since

61 most aquaculture operations exist in open or natural conditions that are subject to changes

62 in the environment, it is important to consider the potential role of epigenetics, particularly

63 now that tools are available to study these important phenomena. Recent studies in species

64 ranging from salmonids to sea bass to oysters and mussels have provided the first evidence

65 that epigenetic mechanisms are associated with commercially important traits in

66 aquaculture species. In sea bass and half-smooth tongue sole, temperature-induced sex-

67 determination has been associated with changes in DNA methylation (Navarro-Martin et al.,

68 2011; Shao et al., 2014). In salmonids, there is some evidence that changes in DNA

69 methylation are associated with variation in life-history phenotypes including early male

70 maturation (Morán \& Pérez-Figueroa, 2011), smoltification (Morán et al., 2013), anadromy

71 (Baerwald et al., 2016) and growth potential (Burgerhout et al., 2017). Recent studies in

72 European sea bass and rainbow trout examined the role of epigenetics in mediating 
73 phenotypic responses to various aspects of diet (Marandel et al., 2016; Terova et al., 2016;

74 Panserat et al., 2017). In Pacific oysters, the role of epigenetics in mediating the effects of 75 temperature on oyster physiology has been investigated (Fellous, Favrel \& Riviere, 2015).

76 Recent efforts have also aimed at understanding the role epigenetics may play in other

77 important phenomena in aquaculture, including sex control via ploidy manipulation

78 (Covelo-Soto et al., 2015; Jiang et al., 2016; Zhou et al., 2016), the effects of inbreeding

79 (Venney et al., 2016) and adaptation to captivity (Le Luyer et al., 2017).

80 This review will introduce key concepts and definitions of epigenetic mechanisms,

81 briefly review the literature as it pertains to the nascent field of epigenetics in aquatic

82 species and highlight key aspects of aquaculture that could benefit from a deeper

83 understanding of the role of epigenetics. Several excellent reviews of epigenetics, primarily

84 DNA methylation, and various aspects of finfish aquaculture (e.g. Li \& Leatherland, 2013;

85 Moghadam, Mørkøre \& Robinson, 2015; Labbe et al., 2017) have recently been published,

86 and these will be highlighted where appropriate.

\section{Survey methodology}

89 The authors have been actively involved in epigenetic research over the past decade,

90 primarily in shellfish, and more recently in finfish (Gavery). As part of this research, we have

91 performed extensive literature searches and literature reviews in numerous venues

92 including, but not limited to, university library catalogs, Web of Science, Google Scholar,

93 Scopus, and general web searches. In addition, we routinely attend local and international

94 workshops and conferences focused on epigenetics in shellfish and fish, where we interact

95 with colleagues who are actively engaged in similar research. Platforms such as Twitter

96 have also been useful for the discovery of new research and associated manuscripts.

\section{What is epigenetics?}

99 The following section will briefly describe specific epigenetic marks and review where we

100 stand in terms of understanding (or not understanding) the relationship between

101 epigenetics, the environment and phenotype in aquaculture species.

102

103 DNA methylation 
104 DNA methylation refers to the enzymatic addition of a methyl group to a cytosine residue in 105 DNA, which occurs almost exclusively at CpG dinucleotides (i.e. a cytosine located 5' of a 106 guanine) in animals. The enzymatic machinery supporting DNA methylation includes a 107 family of DNA methyltransferases (DNMTs), including the maintenance methyltransferase 108 DNMT1 (responsible for copying pre-existing DNA methylation patterns to the new strand 109 during mitosis) and the de novo methyltransferases DNMT3A/3B. DNA methylation is 110 known to be repressive when located in promoters of genes through associations with other 111 DNA-binding proteins or through the physical blocking of transcription factors (Bell $\mathcal{E}$ 112 Felsenfeld, 2000). However, DNA methylation in gene bodies is associated with high levels of 113 expression (Jones, 1999). Therefore, although DNA methylation is typically associated with 114 silencing, its regulatory role is specific to the genomic context. In mammals, DNA 115 methylation plays important roles in providing genomic stability through the repression of 116 transposable elements (TEs) (Maloisel \& Rossignol, 1998), genomic imprinting (Bell \& 117 Felsenfeld, 2000), and dosage compensation (Csankovszki, Nagy \& Jaenisch, 2001). DNA 118 methylation is also important for cell-type differentiation and embryonic development ( $\mathrm{Li}$, 119 Bestor \& Jaenisch, 1992). DNA methylation is the most well-studied epigenetic mechanism, 120 and most studies have been done in plants and mammals, in which DNA methylation has 121 been shown to be sensitive to external factors including nutrition (Weaver et al., 2004), 122 exposure to toxins (Dolinoy et al., 2006), and photoperiod (Azzi et al., 2014). Importantly, 123 the meiotic transmission of DNA methylation patterns, and thus the opportunity for 124 transgenerational epigenetic inheritance through DNA methylation, is rare in mammals, 125 which undergo extensive DNA methylation reprogramming in the early embryo stage 126 (Daxinger \& Whitelaw, 2012). Transgenerational epigenetic inheritance is more common in 127 plants, which do not exhibit extensive resetting of DNA methylation between generations 128 (reviewed by Hauser et al., 2011). As discussed below, it is still unclear if and to what extent 129 DNA methylation resetting occurs in fish and shellfish.

131 Histone variants and post-translational modifications

132 Chromatin is a dynamic structure that supports both packaging of the genome into the 133 nucleus and the regulation of genes and other genomic regions via changes in DNA 134 accessibility (Cheung, Allis \& Sassone-Corsi, 2000). The basic repeating structure of 135 chromatin is the nucleosome, which consists of DNA wrapped around an octamer of four 
136 core histone proteins (H2A, H2B, H3 and H4). Higher-order chromatin structure is

137 established via the incorporation of linker histones (H1) between nucleosomes. Chromatin

138 structure can be modified to either enhance or repress transcription through the

139 incorporation of histone variants and the post-translational modification of histones

140 (Berger, 2007). These modified chromatin states can be inherited both mitotically and

141 meiotically, and thus may convey epigenetic information (Henikoff \& Smith, 2015). Histone

142 variants have specialized functions and can be incorporated into nucleosomes in a

143 replication-independent manner (Henikoff $\mathcal{E}$ Smith, 2015). Although histone variants have

144 been less-studied than post-translational modifications, they can play an important role in

145 mediating both short- and long-term responses to environmental cues (Talbert \& Henikoff,

146 2014). Both canonical and variant histones can be post-translationally modified, primarily

147 at their N-terminal tails, which alters the degree of chromatin compaction resulting in either

148 euchromatin (referring to open chromatin that is accessible to transcription factors, RNA

149 polymerase II (Pol II) and other DNA-binding proteins that support gene expression) or

150 heterochromatin (referring to tightly packed DNA associated with transcriptional silencing).

151 These states are dependent on the type (e.g. acetylation, methylation, phosphorylation,

152 ubiquitylation) and location (e.g. various lysine or arginine residues) of the modification

153 (see review by Lawrence, Daujat \& Schneider, 2016) for a complete list of modifications).

154 These modifications are enabled by various families of enzymes, including histone

155 acetylases (HATs), histone deacetylases (HDACs), histone methyltransferases (e.g. HMT) and

156 histone demethylases (e.g. Jumonji and Lys-specific demethylase). Post-translational

157 modifications are important for the regulation of gene activity, but also play roles in DNA

158 repair, replication, and cell fate/determination (see reviews by Eberharter \& Becker, 2002;

159 Martin \& Zhang, 2005; Lawrence, Daujat \& Schneider, 2016). The enzymatic machinery

160 responsible for these modifications is highly regulated during embryonic development (Lin

161 \& Dent, 2006), and, like DNA methylation, can be altered by various environmental

162 conditions (Chinnusamy $\&$ Zhu, 2009). Less is known about the mechanisms that underlie

163 the mitotic and meiotic persistence of histone modifications. Interestingly, it has been

164 shown in both mammals and zebrafish that certain modified histones are non-randomly

165 retained during spermatogenesis when most of these proteins are replaced by protamines,

166 suggesting that these marks may play a role in transferring epigenetic information to the

167 embryo (Brykczynska et al., 2010; Wu, Zhang \& Cairns, 2011). 
170 Although a large majority of the genome is transcribed, only a small portion of these

171 transcripts actually code for protein. The remaining non-coding transcripts, originally

172 regarded as 'junk', are now recognized to play a role in modulating gene expression, and are

173 categorized broadly as non-coding RNA (ncRNA). There are two major classes of ncRNA:

174 long ncRNA ( > $200 \mathrm{nt}$ ) and small ncRNA (< $200 \mathrm{nt}$ ), the latter of which includes micro RNA

175 (miRNA), short interfering RNA (siRNA), and PIWI-interacting RNA (piRNA). Small ncRNAs

176 are highly conserved and their major mechanism of action is to inhibit protein synthesis by

177 blocking or degrading primary transcripts (see review by Castel \& Martienssen, 2013). In

178 contrast, long ncRNAs (lncRNA) are less conserved and have complex mechanisms of action

179 that may work either in cis or trans (see review by Wang $\&$ Chang, 2011). Non-coding RNAs

180 have important functions in gene expression and have been demonstrated to be important

181 regulators of genome stability, environmental plasticity and embryonic development

182 (Mercer, Dinger \& Mattick, 2009; Bizuayehu \& Babiak, 2014). Generally, ncRNA molecules

183 are considered to be 'epigenetic' in the traditional sense because they interact with other

184 epigenetic mechanisms such as DNA methylation and histone modifications to silence or

185 activate various parts of the genome (Peschansky \& Wahlestedt, 2014). There is also

186 evidence that ncRNA, particularly miRNA, plays a role in the transmission of environmental

187 information from the male parent (via sperm) to offspring in mammals (Gapp et al., 2014;

188 Rodgers et al., 2015). Evidence of transgenerational inheritance through miRNA has also

189 been observed in the invertebrate model C. elegans in response to starvation (Rechavi et al., 190 2014) and temperature (Klosin et al., 2017) cues.

191 Taxa specific Patterns

192

193 Epigenetic mechanisms, and particularly DNA methylation, have recently been the 194 focus of numerous studies in both fish and shellfish. However, most of what we know about 195 epigenetics in animals comes from studies done in mammals and care should be taken when 196 generalizing results in mammals to fish and shellfish. Although there are certainly

197 similarities (e.g. DNA methylation patterns are very similar across all vertebrates), there are 198 also important differences (e.g. invertebrate DNA methylation patterns are very different 
199 from those in vertebrates). This section will focus on foundational information about

200 epigenetic marks in fish and shellfish, and highlight both significant gaps in our

201 understanding and differences from well-studied mammalian systems.

202

203 DNA methylation in fish and shellfish

204 DNA methylation is the most well-studied epigenetic mark among fish and shellfish. Both

205 fish and shellfish have genes that encode the basic methylation machinery (e.g. DNMTs and

206 MBDs) and DNA methylation is present in all species examined to date. However, there are

207 striking differences in DNA methylation patterns between vertebrates and invertebrates, as

208 well as significant unknowns in terms of the resetting of DNA methylation in both fish and

209 shellfish, which will be described below.

210 Considerable work has been done on understanding patterns and functions of DNA

211 methylation in model fish species such as zebrafish and medaka, and there is also a growing

212 body of information on DNA methylation in non-model species (e.g. Metzger \& Schulte

213 (2016) reviewed the current state of knowledge of DNA methylation patterns and functions

214 in marine fish). Generally, DNA methylation patterns are similar across all vertebrates that

215 exhibit a 'global' DNA methylation pattern, which means that most CpGs are methylated

216 with the exception of regions of DNA with a high $\mathrm{CpG}$ content (referred to as $\mathrm{CpG}$ islands).

217 However, global DNA methylation levels in fish are higher than those in mammals, though

218 the significance of this difference remains unclear (Jabbari et al., 1997; Zhang, Hoshida \&

219 Sadler, 2016). The function of DNA methylation also appears to be similar across

220 vertebrates, with the exception that its role in parental imprinting is likely unique to

221 mammals (Barlow \& Bartolomie, 2014). One outstanding question concerns the extent of

222 DNA methylation resetting in fish. While mammals undergo extensive DNA methylation

223 reprogramming in the early embryo (Daxinger \& Whitelaw, 2012), the extent of DNA

224 methylation reprogramming in fish is unclear (Jiang et al., 2013; Potok et al., 2013). A recent

225 study, which is discussed in more detail in the following section, showed clear evidence of

226 transgenerational inheritance of environmentally-induced DNA methylation patterns in a

227 fish, suggesting that at least some of the genome escapes putative resetting between

228 generations (Shao et al., 2014). There is a need for more detailed studies on the extent of

229 DNA methylation resetting in fish, particularly in species used in aquaculture. In addition, 
230 more studies should examine the potential meiotic inheritance of environmentally-induced 231 epigenetic changes.

232 Invertebrate DNA methylation patterns are strikingly different from those in 233 vertebrates. Whereas vertebrates exhibit a global pattern of DNA methylation, invertebrates 234 show a 'mosaic' pattern, with stretches of methylated DNA punctuating regions of 235 unmethylated DNA (Tweedie et al., 1997; Simmen et al., 1999). We previously examined 236 DNA methylation throughout the entire genome in the Pacific oyster; $15 \%$ of CpGs in 237 somatic tissue were methylated, whereas 60-70\% of CpGs are methylated in mammals 238 (Gavery \& Roberts, 2013). In oysters, as in other invertebrates, the methylated fraction 239 tends to consist of gene bodies, while other genomic regions exhibit less methylation. Unlike 240 vertebrate species, transposable elements in oysters and other invertebrate species show 241 surprisingly little methylation (Simmen et al., 1999; Feng et al., 2010; Zemach et al., 2010).

242 Despite these differences, DNA methylation does appear to be associated with gene 243 regulation in shellfish. In the Pacific oyster, high levels of methylation in gene bodies are 244 associated with high levels of expression (Gavery \& Roberts, 2013; Olson \& Roberts, 2014).

245 Interestingly, genes in oysters with limited methylation show variable exon-specific 246 expression across tissue types, indicating that hypomethylation allows increased plasticity 247 (Gavery \& Roberts, 2013). DNA methylation patterns in the Pacific oyster are dynamic 248 across developmental stages, and correlations between DNA methylation and gene 249 expression patterns suggest that DNA methylation plays a role in gene regulation during 250 development (Riviere et al., 2017). While more studies are needed to quantify the functional 251 relationship between DNA methylation and gene expression, there are significant 252 implications for improving resilience in shellfish - particularly if DNA methylation patterns 253 are heritable. While few studies have examined the heritability of DNA methylation patterns 254 in shellfish, a small study that focused on methylation states in parents and larvae found a 255 significant clustering of methylation patterns within families, indicating that methylation 256 patterns differ significantly depending on the male parent (Olson \& Roberts, 2015). More 257 recently, Rondon et al. (2017) showed that parental exposure to an herbicide influences 258 progeny DNA methylation patterns in oysters. 
Histone variants and post-translational modifications have generally been studied in

261 model fish species, such as zebrafish. Some histone variants show a conserved function

262 between lower vertebrates and mammals. For example, histone variant macroH2A has been

263 shown to play an important role in development in the zebrafish (Buschbeck et al., 2009).

264 However, while some histone variants are 'universal' and can be found in most eukaryotes

265 (Talbert \& Henikoff, 2010), other histone variants appear to be unique to fish (Wu et al., 266 2009).

267 Post-translational modifications of histones and their dynamics have also been 268 studied in zebrafish, and the evidence indicates that modifications are conserved among 269 vertebrates. The functional analysis of histone acetylation in zebrafish confirms that it plays 270 a role in embryogenesis (Vastenhouw \& Schier, 2012) and in tissue regeneration (Stewart, 271 Hoshida \& Sadler, 2009). While studies of histone modification in non-model fish are rare, 272 recent studies in rainbow trout and European sea bass indicate that diet influences bulk 273 histone modification levels and can regulate the expression of associated enzymes 274 (Marandel et al., 2016; Terova et al., 2016; Panserat et al., 2017). With regard to meiotic 275 inheritance, zebrafish show multivalent modified histone retention in sperm, similar to 276 mammals (Wu, Zhang \& Cairns, 2011).

277 Histone variants have been characterized in various bivalve species (e.g. González278 Romero et al., 2009; González-Romero et al., 2012) and a recent study on the responses of 279 Eastern oysters to harmful algal blooms reported that the histone variant H2A.X is post280 translationally modified in response to algal toxins (González-Romero et al., 2017). While 281 post-translational modifications of histones are not well-studied in shellfish, Fellous et al. 282 (2014) identified homologs of Jumonji histone demethylase genes (Jmj) in Pacific oysters 283 that, as in vertebrates, were regulated during embryonic development. A subsequent study 284 showed that both bulk histone methylation levels and the expression of histone 285 demethylases responded to temperature during development, suggesting that histone 286 modifications play a role in mediating the physiological responses of oysters to temperature 287 (Fellous, Favrel \& Riviere, 2015).

$288 \quad$ Histones are not replaced by protamines in bivalve sperm as they are in mammals 289 (Eirin-Lopez \& Ausio, 2009). Rather, depending on the species, canonical histones are 290 replaced by various sperm nuclear basic proteins that can be classified as either protamine291 like-type, histone-type or protamine-type (Ausio, 1986; Eirin-Lopez \& Ausio, 2009). Further 
292 studies will be needed to determine the extent to which canonical histones and variants are 293 retained in bivalve sperm, and this avenue of research could greatly contribute to a greater 294 understanding of the potential transmission of epigenetic information from parent to 295 offspring in bivalves. Recent work on the details of experimental approaches and workflows 296 for the study of chromatin-associated proteins in bivalves (Rivera-Casas et al., 2017) should 297 facilitate this research.

298 Non-coding RNA in fish and shellfish

299 Most studies on non-coding RNAs in fish and shellfish, including important 300 aquaculture species (e.g. Atlantic salmon (Andreassen, Worren \& Høyheim, 2013; Bekaert et 301 al., 2013) and rainbow trout (Juanchich et al., 2016)), have focused on miRNAs. There have 302 been several studies of miRNAs in a physiological context, including in eggs (e.g. Ma et al., 303 2012), immune function (e.g. Andreassen \& Høyheim, 2017) and embryo development 304 (Bizuayehu et al., 2015). There is less information available about other types of small 305 ncRNA, except in zebrafish where, for example, piRNA has been shown to silence 306 transposable elements in gametes, and thus functions similarly to that in mammals 307 (Houwing et al., 2007). Recently, there have been several descriptions of long non-coding 308 RNAs in salmonids, including associations between lncRNA expression and disease in both 309 Atlantic salmon and rainbow trout (Boltaña et al., 2016; Paneru et al., 2016; Valenzuela310 Miranda et al., 2016).

311 While there have been few studies on non-coding RNAs in shellfish, generally,

312 miRNAs and their biogenesis are highly conserved over evolutionary scales (Wheeler et al.,

313 2009). Indeed, genes for miRNA biogenesis have been detected in available bivalve genomes

314 (Rosani, Pallavicini \& Venier, 2016). With respect to long non-coding RNAs, researchers 315 have reported an association between lncRNAs and larval development in the Pacific oyster 316 (Yu, Zhao \& Li, 2016).

317

\section{Potential Aquaculture Applications}

\section{Environmental manipulation}

320 Given what we know about environmental influences on epigenetic mechanisms in fish and 321 shellfish and the relationships between these mechanisms and phenotype, a potentially 
322 fruitful application of epigenetics to aquaculture could involve environmental manipulation.

323 The possibility of generating environmentally-driven phenotypes mediated through

324 epigenetic mechanisms should be considered for two stages in the aquaculture life-cycle in

325 which the animals are particularly sensitive: during larval development and during

326 broodstock holding/conditioning (Figure 1).

327 The notion of developmental programming suggests that environmental conditions

328 experienced in early life influence the phenotype later in life, and has gained momentum in

329 human research (e.g. Gluckman et al., 2008). Thus, developmental programming offers a

330 memory of the environment that could be beneficial in controlled aquaculture settings.

331 However, in some cases, embryos and juveniles are not raised in the same environmental

332 conditions as the adults. For example, hatchery-reared salmon or bivalves experience very

333 different conditions during their larval and adult stages. The identification of sensitive

334 periods for inducing an environmental memory could offer a "programming window" that

335 could be leveraged in husbandry practices. Several lines of evidence support the presence of

336 developmental programming in fish (for an excellent review see Jonsson \& Jonsson, 2014).

337 Traits that have been associated with early environmental conditions include metabolism,

338 growth, sex determination, fecundity, and behavior (Jonsson \& Jonsson, 2014). Within-

339 generation environmental memory has also been described in shellfish. For example, early

340 exposure of Olympia oyster larvae to ocean acidification has been shown to influence

341 juvenile traits (Hettinger et al., 2012).

342 Two examples of developmental programming in aquaculture, where the epigenetic

343 mechanisms were described, involve sex determination in fish. In European sea bass

344 (Dicentrarchus labrax), exposure to high temperature in early development was associated

345 with a higher proportion of phenotypic males (Navarro-Martin et al., 2009). Navarro-Martin

346 et al. (2011) found that this early exposure to high temperature was associated with

347 increased DNA methylation in the promoter of the aromatase gene (cyp19a1a) in adults.

348 Furthermore, they showed that in vitro methylation of the aromatase promoter was

349 sufficient to suppress transcription of the gene. More recently, the commercially important

350 half-smooth tongue sole (Cynoglossus semilaevis) was used as a model to investigate the role

351 of epigenetic regulation in environmental sex determination (Shao et al. 2014). Using

352 genome-wide DNA methylation profiling, the authors showed that pseudomales (generated

353 by exposing genetic females to high temperature during a sensitive developmental window) 
354 exhibit methylation patterns in testes consistent with genetic males, both of which differ 355 from the ovarian methylome of normal females. Excitingly, it was reported that both the 356 pseudomale phenotype and the testes-specific methylation patterns are inherited by F1 357 pseudomale offspring generated by crosses between pseudomales and normal females, 358 suggesting the transgenerational epigenetic inheritance of environmentally-induced sex 359 reversal in this species (Shao et al., 2014). The ability to control sex in fish broodstock is 360 certainly a priority for aquaculture and these studies shed light on the epigenetic 361 mechanisms that could be leveraged in future work. More studies will be needed to 362 determine the extent to which the relevant mechanisms are conserved across species that 363 exhibit environmental sex determination.

$364 \quad$ Nutrition and feeding are important aspects of aquaculture production; and 365 understanding how early-life nutritional conditions influence key phenotypic traits later in 366 life is important to consider. In mammals, the nutritional status of the mother can 367 predispose offspring to adult-onset metabolic disease and mounting evidence suggests that 368 epigenetic mechanisms are involved (reviewed by Vickers, 2014). In fish, rainbow trout fry 369 fed a plant-based diet for 3 weeks starting when they were swim-up fry showed higher 370 growth rates, feed intakes, and feed efficiencies when challenged again with a plant-based 371 diet after 7 months of grow-out on a fishmeal/fish oil diet (Geurden et al., 2013).

372 Interestingly, in a follow-up study, transcriptomic analyses suggested that epigenetic 373 mechanisms may be involved in this response (Balasubramanian et al., 2016). In addition, a 374 study on vitamin supplementation at first feeding in rainbow trout identified changes in 375 global methylation and histone modification 7 months after the supplementation was 376 discontinued, despite an apparent lack of phenotypic responses (Panserat et al., 2017). 377 These studies provide the first link between early-environmental exposure and epigenetic 378 mechanisms in aquaculture species.

379 In addition to developmental programming, broodstock holding/conditioning is also 380 an important area to consider for the potential transmission of environmentally-induced 381 epigenetic information between parents and their offspring. This type of non-genetic 382 transmission is frequently referred to as 'transgenerational plasticity' (Salinas et al., 2013) 383 and can refer both to maternal provisioning (e.g. bivalve embryos can be influenced by the 384 type of diet fed to broodstock during conditioning (Utting \& Millican, 1997)) and epigenetic 385 inheritance. Importantly, epigenetic transmission has the potential to be transmitted not 
386 only from the maternal side, but also from the paternal side, which may be more important 387 than previously thought (Rodgers et al., 2015; reviewed by Soubry et al., 2014). There has 388 been growing interest in the transgenerational plasticity of fish, particularly as it relates to 389 predicting responses to climate change (reviewed by Munday, 2014). Similar research 390 questions are also being addressed in shellfish. Adult Manila clams exposed to low $\mathrm{pH}$ 391 during gonadal maturation have faster-growing offspring compared to controls (Zhao et al., 392 2017). In the Sydney rock oyster, larvae produced by parents incubated under low-pH 393 conditions are larger and develop faster in low-pH conditions and also have higher fitness 394 as adults (Parker et al., 2012; Parker et al., 2015). In addition to water chemistry, disease is 395 a significant concern in shellfish aquaculture. There is increasing evidence that prior 396 exposure to an immune challenge can increase the immune response later in life and that 397 this environmental memory can be transmitted to offspring. Green et al. (2016)

398 demonstrated that offspring of Pacific oyster parents treated with poly(I:C) possess 399 enhanced protection against Ostreid herpesvirus type I infection.

400 The mechanism(s) responsible for providing this memory of the environment in 401 cultured species are not fully understood. While such an understanding is, arguably, not 402 required to improve aquaculture production, we would suggest that elucidation of the 403 epigenetic mechanisms involved could increase the degree and breadth of ongoing 404 improvements.

\section{Epigenetic selection}

406 It is possible that epigenetic markers could be integrated into broodstock selection. The 407 concept of epigenetic selection has gone from theory to practice in one important 408 agriculture commodity, oil palms, where it has been shown that it is possible to 409 epigenetically select for a critical trait: oil content (Ong-Abdullah et al., 2015). While there is 410 much more we need to learn with regard to desired phenotypes and epialleles, work such as 411 this demonstrates that it can be useful to consider epigenetics in association studies.

412 Furthermore, Patel et al. (2013)_showed in a clinical study that the use of both genetic (SNP) 413 and epigenetic (DNA methylation) markers in genome-wide association studies improved 414 associations with a phenotype (i.e. diabetes). The influence of epigenetics, specifically DNA 415 methylation, on the ability to estimate breeding values for quantitative traits has recently 
416 been considered for finfish aquaculture (see the review by Moghadam, Mørkøre \& 417 Robinson, 2015).

418 Epigenetics could also make genetic selection more challenging. Many organisms 419 have the potential to generate new genetic variations in response to stressful conditions 420 through the modulation of epigenetic marks associated with transposable elements (TEs) 421 (Dowen et al., 2012; Yu et al., 2013; reviewed by Rey et al., 2016). Transposable elements, or 422 “jumping genes", are regions of repetitive DNA that can move and amplify their copy 423 number in the host genome. In the model plant Arabidopsis, the genomic response to 424 bacterial challenge is a global reduction of DNA methylation and the reactivation of 425 previously silent TEs associated with defense genes (Yu et al., 2013). It is interesting to 426 consider that in invertebrates, and specifically in Pacific oysters, TEs are not preferentially 427 methylated, though this does not preclude silencing via other epigenetic mechanisms 428 (Gavery \& Roberts, 2013; Olson \& Roberts, 2015). It has been hypothesized that the lack of 429 TE silencing by DNA methylation may indicate pressure to generate and maintain genetic 430 diversity in a species that inhabits heterogeneous environments (Gavery \& Roberts, 2014). 431 This means that, in theory, if the culture conditions become stressful, shellfish could 432 respond by modulating transposable element expression to create new genetic variation 433 (Rey et al., 2016), thereby having the unintended consequence of "erasing” phenotypic gains 434 made through selective breeding.

\section{Conclusions}

438 Epigenetics has the potential to change the way we think about how a phenotype is 439 generated and maintained. Through a greater understanding of DNA methylation, histone 440 modifications and ncRNAs, we can functionally annotate genomes, better predict 441 phenotypic outcomes of early environmental exposures, and possibly select based on 442 epigenetic markers. With careful experimental design and special considerations for 443 epigenetic differences between taxa (see Lea et al., 2016), the aquaculture community is 444 primed to begin to integrate epigenetics into husbandry practices. The concepts and ideas 445 of epigenetics provide an attractive lens through which to consider the manipulation of 446 traits through environmental memory or the selection of beneficial traits based on 
447 epigenetic markers. It is also important to consider that epigenetics may also function to

448 disrupt predictable, robust phenotypes through the creation of new, unexpected variation. 449

450 Acknowledgements

451 The authors would like to thank Guillaume Rivière and the anonymous reviewer for their

452 helpful and constructive comments that greatly contributed to improving the final

453 version of the paper.

454 References

455 Álvarez-Venegas R., De-la-Peña C. 2016. Editorial: Recent Advances of Epigenetics in Crop 456 Biotechnology. Frontiers in plant science 7:413.

457 Andreassen R., Worren MM., Høyheim B. 2013. Discovery and characterization of miRNA

458 genes in atlantic salmon (Salmo salar) by use of a deep sequencing approach. BMC genomics $45914: 482$.

460 Artemov AV., Mugue NS., Rastorguev SM., Zhenilo S., Mazur AM., Tsygankova SV., Boulygina 461 ES., Kaplun D., Nedoluzhko AV., Medvedeva YA., Prokhortchouk EB. 2017. Genome-Wide 462 DNA Methylation Profiling Reveals Epigenetic Adaptation of Stickleback to Marine and 463 Freshwater Conditions. Molecular biology and evolution 34:2203-2213.

464 Azzi A., Dallmann R., Casserly A., Rehrauer H., Patrignani A., Maier B., Kramer A., Brown SA. 465 2014. Circadian behavior is light-reprogrammed by plastic DNA methylation. Nature 466 neuroscience 17:377-382.

467 Baerwald MR., Meek MH., Stephens MR., Nagarajan RP., Goodbla AM., Tomalty KMH., 468 Thorgaard GH., May B., Nichols KM. 2016. Migration-related phenotypic divergence is 469 associated with epigenetic modifications in rainbow trout. Molecular ecology 25:17854701800.

471 Balasubramanian MN., Panserat S., Dupont-Nivet M., Quillet E., Montfort J., Le Cam A., 472 Medale F., Kaushik SJ., Geurden I. 2016. Molecular pathways associated with the nutritional 
473 programming of plant-based diet acceptance in rainbow trout following an early feeding 474 exposure. BMC genomics 17:449.

475 Barlow DP., Bartolomei MS. 2014. Genomic imprinting in mammals. Cold Spring Harbor 476 perspectives in biology 6. DOI: 10.1101/cshperspect.a018382.

477 Bekaert M., Lowe NR., Bishop SC., Bron JE., Taggart JB., Houston RD. 2013. Sequencing and 478 Characterisation of an Extensive Atlantic Salmon (Salmo salar L.) MicroRNA Repertoire. 479 PloS one 8:e70136.

480 Bell AC., Felsenfeld G. 2000. Methylation of a CTCF-dependent boundary controls imprinted 481 expression of the Igf2 gene. Nature 405:482-485.

482 Bell JT., Pai AA., Pickrell JK., Gaffney DJ., Pique-Regi R., Degner JF., Gilad Y., Pritchard JK. 2011. 483 DNA methylation patterns associate with genetic and gene expression variation in HapMap 484 cell lines. Genome biology 12:R10.

485 Berger SL. 2007. The complex language of chromatin regulation during transcription. 486 Nature 447:407-412.

487 Bizuayehu TT., Babiak I. 2014. MicroRNA in teleost fish. Genome biology and evolution 488 6:1911-1937.

489 Bizuayehu TT., Johansen SD., Puvanendran V., Toften H., Babiak I. 2015. Temperature during 490 early development has long-term effects on microRNA expression in Atlantic cod. BMC 491 genomics 16:305.

492 Boltaña S., Valenzuela-Miranda D., Aguilar A., Mackenzie S., Gallardo-Escárate C. 2016. Long 493 noncoding RNAs (lncRNAs) dynamics evidence immunomodulation during ISAV-Infected 494 Atlantic salmon (Salmo salar). Scientific reports 6:22698.

495 Brykczynska U., Hisano M., Erkek S., Ramos L., Oakeley EJ., Roloff TC., Beisel C., Schübeler D., 496 Stadler MB., Peters AHFM. 2010. Repressive and active histone methylation mark distinct 497 promoters in human and mouse spermatozoa. Nature structural \& molecular biology 498 17:679-687. 
499 Burgerhout E., Mommens M., Johnsen H., Aunsmo A., Santi N., Andersen Ø. 2017. Genetic

500 background and embryonic temperature affect DNA methylation and expression of

501 myogenin and muscle development in Atlantic salmon (Salmo salar). PloS one 12:e0179918.

502 Buschbeck M., Uribesalgo I., Wibowo I., Rué P., Martin D., Gutierrez A., Morey L., Guigó R., 503 López-Schier H., Di Croce L. 2009. The histone variant macroH2A is an epigenetic regulator 504 of key developmental genes. Nature structural \& molecular biology 16:1074-1079.

505 Campos C., Valente LMP., Conceição LEC., Engrola S., Fernandes JMO. 2013. Temperature

506 affects methylation of the myogenin putative promoter, its expression and muscle cellularity 507 in Senegalese sole larvae. Epigenetics: official journal of the DNA Methylation Society 8:389508397.

509 Castel SE., Martienssen RA. 2013. RNA interference in the nucleus: roles for small RNAs in 510 transcription, epigenetics and beyond. Nature reviews. Genetics 14:100-112.

511 Cheung P., Allis CD., Sassone-Corsi P. 2000. Signaling to chromatin through histone 512 modifications. Cell 103:263-271.

513 Chinnusamy V., Zhu J-K. 2009. Epigenetic regulation of stress responses in plants. Current 514 opinion in plant biology 12:133-139.

515 Covelo-Soto L., Leunda PM., Pérez-Figueroa A., Morán P. 2015. Genome-wide methylation 516 study of diploid and triploid brown trout (Salmo trutta L.). Animal genetics 46:280-288.

517 Csankovszki G., Nagy A., Jaenisch R. 2001. Synergism of Xist RNA, DNA methylation, and 518 histone hypoacetylation in maintaining X chromosome inactivation. The Journal of cell 519 biology 153:773-784.

520 Daxinger L., Whitelaw E. 2012. Understanding transgenerational epigenetic inheritance via 521 the gametes in mammals. Nature reviews genetics 13:153-162.

522 Dolinoy DC., Weidman JR., Waterland RA., Jirtle RL. 2006. Maternal genistein alters coat 523 color and protects Avy mouse offspring from obesity by modifying the fetal epigenome. 524 Environmental health perspectives 114:567-572. 
525 Dowen RH., Pelizzola M., Schmitz RJ., Lister R., Dowen JM., Nery JR., Dixon JE., Ecker JR. 2012.

526 Widespread dynamic DNA methylation in response to biotic stress. Proceedings of the

527 National Academy of Sciences of the United States of America 109:E2183-91.

528 Eberharter A., Becker PB. 2002. Histone acetylation: a switch between repressive and 529 permissive chromatin. Second in review series on chromatin dynamics. EMBO reports $530 \quad 3: 224-229$.

531 Eirín-López JM., Ausió J. 2009. Origin and evolution of chromosomal sperm proteins.

532 BioEssays: news and reviews in molecular, cellular and developmental biology 31:1062-1070.

533 Fellous A., Favrel P., Guo X., Riviere G. 2014. The Jumonji gene family in Crassostrea gigas 534 suggests evolutionary conservation of Jmj-C histone demethylases orthologues in the oyster 535 gametogenesis and development. Gene 538:164-175.

536 Fellous A., Favrel P., Riviere G. 2015. Temperature influences histone methylation and mRNA 537 expression of the Jmj-C histone-demethylase orthologues during the early development of 538 the oyster Crassostrea gigas. Marine genomics 19:23-30.

539 Feng S., Cokus SJ., Zhang X., Chen P-Y., Bostick M., Goll MG., Hetzel J., Jain J., Strauss SH., 540 Halpern ME., Ukomadu C., Sadler KC., Pradhan S., Pellegrini M., Jacobsen SE. 2010.

541 Conservation and divergence of methylation patterning in plants and animals. Proceedings 542 of the National Academy of Sciences of the United States of America 107:8689-8694.

543 Frehlick LJ., Eirín-López JM., Prado A., Su HWH., Kasinsky HE., Ausió J. 2006. Sperm nuclear 544 basic proteins of two closely related species of Scorpaeniform fish (Sebastes maliger, 545 Sebastolobus sp.) with different sexual reproduction and the evolution of fish protamines. 546 Journal of experimental zoology. Part A, Comparative experimental biology 305:277-287.

547 Gapp K., Jawaid A., Sarkies P., Bohacek J., Pelczar P., Prados J., Farinelli L., Miska E., Mansuy 548 IM. 2014. Implication of sperm RNAs in transgenerational inheritance of the effects of early 549 trauma in mice. Nature neuroscience 17:667-669.

550 Gavery MR., Roberts SB. 2013. Predominant intragenic methylation is associated with gene 551 expression characteristics in a bivalve mollusc. PeerJ 1:e215. 
552 Gavery MR., Roberts SB. 2014. A context dependent role for DNA methylation in bivalves.

553 Briefings in functional genomics 13:217-222.

554 Geurden I., Borchert P., Balasubramanian MN., Schrama JW., Dupont-Nivet M., Quillet E., 555 Kaushik SJ., Panserat S., Médale F. 2013. The Positive Impact of the Early-Feeding of a Plant556 Based Diet on Its Future Acceptance and Utilisation in Rainbow Trout. PloS one 8:e83162.

557 Gluckman PD., Hanson MA., Cooper C., Thornburg KL. 2008. Effect of in utero and early-life 558 conditions on adult health and disease. The New England journal of medicine 359:61-73.

559 Goddard ME., Whitelaw E. 2014. The use of epigenetic phenomena for the improvement of 560 sheep and cattle. Frontiers in genetics 5:247.

561 González-Recio O., Toro MA., Bach A. 2015. Past, present, and future of epigenetics applied 562 to livestock breeding. Frontiers in genetics 6:305.

563 González-Romero R., Ausió J., Méndez J., Eirín-López JM. 2009. Histone genes of the razor 564 clam Solen marginatus unveil new aspects of linker histone evolution in protostomes.

565 Genome 52:597-607.

566 González-Romero R., Rivera-Casas C., Frehlick LJ., Méndez J., Ausió J., Eirín-López JM. 2012. 567 Histone H2A (H2A.X and H2A.Z) variants in molluscs: molecular characterization and 568 potential implications for chromatin dynamics. PloS one 7:e30006.

569 Gonzalez-Romero R., Suarez-Ulloa V., Rodriguez-Casariego J., Garcia-Souto D., Diaz G., Smith 570 A., Pasantes JJ., Rand G., Eirin-Lopez JM. 2017. Effects of Florida Red Tides on histone variant 571 expression and DNA methylation in the Eastern oyster Crassostrea virginica. Aquatic 572 toxicology 186:196-204.

573 Green TJ., Helbig K., Speck P., Raftos DA. 2016. Primed for success: Oyster parents treated 574 with poly(I:C) produce offspring with enhanced protection against Ostreid herpesvirus type 575 I infection. Molecular immunology 78:113-120.

576 Guerrero-Bosagna C., Settles M., Lucker B., Skinner MK. 2010. Epigenetic transgenerational 577 actions of vinclozolin on promoter regions of the sperm epigenome. PloS one 5. DOI: 578 10.1371/journal.pone.0013100. 
579 Hauser M-T., Aufsatz W., Jonak C., Luschnig C. 2011. Transgenerational epigenetic 580 inheritance in plants. Biochimica et biophysica acta 1809:459-468.

581 Heijmans BT., Tobi EW., Stein AD., Putter H., Blauw GJ., Susser ES., Slagboom PE., Lumey LH. 582 2008. Persistent epigenetic differences associated with prenatal exposure to famine in 583 humans. Proceedings of the National Academy of Sciences of the United States of America $584 \quad 105: 17046-17049$.

585 Henikoff S., Smith MM. 2015. Histone variants and epigenetics. Cold Spring Harbor 586 perspectives in biology 7:a019364.

587 Hettinger A., Sanford E., Hill TM., Russell AD., Sato KNS., Hoey J., Forsch M., Page HN., Gaylord 588 B. 2012. Persistent carry-over effects of planktonic exposure to ocean acidification in the 589 Olympia oyster. Ecology 93:2758-2768.

590 Houwing S., Kamminga LM., Berezikov E., Cronembold D., Girard A., van den Elst H., Filippov 591 DV., Blaser H., Raz E., Moens CB., Plasterk RHA., Hannon GJ., Draper BW., Ketting RF. 2007. A 592 role for Piwi and piRNAs in germ cell maintenance and transposon silencing in Zebrafish. 593 Cell 129:69-82.

594 Jabbari K., Cacciò S., Païs de Barros JP., Desgrès J., Bernardi G. 1997. Evolutionary changes in 595 CpG and methylation levels in the genome of vertebrates. Gene 205:109-118.

596 Jablonka E., Lamb MJ. 2002. The changing concept of epigenetics. Annals of the New York 597 Academy of Sciences 981:82-96.

598 Jenuwein T., Allis CD. 2001. Translating the histone code. Science 293:1074-1080.

599 Jiang Q., Li Q., Yu H., Kong L-F. 2013. Genetic and epigenetic variation in mass selection 600 populations of Pacific oyster Crassostrea gigas. Genes \& genomics 35:641-647.

601 Jiang Q., Li Q., Yu H., Kong L. 2016. Inheritance and Variation of Genomic DNA Methylation in 602 Diploid and Triploid Pacific Oyster (Crassostrea gigas). Marine biotechnology 18:124-132.

603 Jones PA. 1999. The DNA methylation paradox. Trends in genetics: TIG 15:34-37. 
604 Jonsson B. , Jonsson N. 2014. Early environment influences later performance in fishes. 605 Journal of fish biology. 85: 151-188.

606 Juanchich A., Bardou P., Rué O., Gabillard J-C., Gaspin C., Bobe J., Guiguen Y. 2016.

607 Characterization of an extensive rainbow trout miRNA transcriptome by next generation 608 sequencing. BMC genomics $17: 164$.

609 Klosin A., Casas E., Hidalgo-Carcedo C., Vavouri T., Lehner B. 2017. Transgenerational

610 transmission of environmental information in C. elegans. Science 356:320-323.

611 Knecht AL., Truong L., Marvel SW., Reif DM., Garcia A., Lu C., Simonich MT., Teeguarden JG., 612 Tanguay RL. 2017. Transgenerational inheritance of neurobehavioral and physiological 613 deficits from developmental exposure to benzo[a]pyrene in zebrafish. Toxicology and 614 applied pharmacology 329:148-157.

615 Labbé C., Robles V., Herraez MP. 2017. Epigenetics in fish gametes and early embryo. 616 Aquaculture 472:93-106.

617 Lawrence M., Daujat S., Schneider R. 2016. Lateral Thinking: How Histone Modifications 618 Regulate Gene Expression. Trends in genetics: TIG 32:42-56.

619 Le Luyer J., Laporte M., Beacham TD., Kaukinen KH., Withler RE., Leong JS., Rondeau EB., 620 Koop BF., Bernatchez L. 2017. Parallel epigenetic modifications induced by hatchery rearing 621 in a Pacific Salmon. bioRxiv:148577. DOI: 10.1101/148577.

622 Lea A., Vilgalys T., Durst P., Tung J. 2017. Maximizing ecological and evolutionary insight 623 from bisulfite sequencing data sets. Nature ecology and evolution 1:1074

624 Li E., Bestor TH., Jaenisch R. 1992. Targeted mutation of the DNA methyltransferase gene 625 results in embryonic lethality. Cell 69:915-926.

626 Li M., Leatherland JF. 2013. The implications for aquaculture practice of epigenomic 627 programming of components of the endocrine system of teleostean embryos: lessons 628 learned from mammalian studies. Fish and fisheries 14:528-553. 
629 Lin W., Dent S.Y. 2006. Functions of histone-modifying enzymes in development. Current 630 opinion in genetics and development 16:137-142.

631 Ma H., Hostuttler M., Wei H., Rexroad CE 3rd., Yao J. 2012. Characterization of the rainbow 632 trout egg microRNA transcriptome. PloS one 7:e39649.

633 Maloisel L., Rossignol JL. 1998. Suppression of crossing-over by DNA methylation in 634 Ascobolus. Genes \& development 12:1381-1389.

635 Manikkam M., Guerrero-Bosagna C., Tracey R., Haque MM., Skinner MK. 2012.

636 Transgenerational Actions of Environmental Compounds on Reproductive Disease and 637 Identification of Epigenetic Biomarkers of Ancestral Exposures. PloS one 7:e31901.

638 Marandel L., Lepais O., Arbenoits E., Véron V., Dias K., Zion M., Panserat S. 2016. Remodelling 639 of the hepatic epigenetic landscape of glucose-intolerant rainbow trout (Oncorhynchus 640 mykiss) by nutritional status and dietary carbohydrates. Scientific reports 6:32187.

641 Martin C., Zhang Y. 2005. The diverse functions of histone lysine methylation. Nature 642 reviews. Molecular cell biology 6:838-849.

643 Mercer TR., Dinger ME., Mattick JS. 2009. Long non-coding RNAs: insights into functions. 644 Nature reviews. Genetics 10:155-159.

645 Metzger DCH., Schulte PM. 2016. Epigenomics in marine fishes. Marine genomics 30:43-54.

646 Moghadam H., Mørkøre T., Robinson N. 2015. Epigenetics-Potential for Programming Fish 647 for Aquaculture? Journal of marine science and engineering 3:175-192.

648 Morán P., Marco-Rius F., Megías M., Covelo-Soto L., Pérez-Figueroa A. 2013. Environmental 649 induced methylation changes associated with seawater adaptation in brown trout. 650 Aquaculture 392-395. DOI: 10.1016/j.aquaculture.2013.02.006.

651 Morán P., Pérez-Figueroa A. 2011. Methylation changes associated with early maturation 652 stages in the Atlantic salmon. BMC genetics 12:86.

653 Munday PL. 2014. Transgenerational acclimation of fishes to climate change and ocean 654 acidification. F1000prime reports 6:99. 
655 Navarro-Martín L., Blázquez M., Viñas J., Joly S., Piferrer F. 2009. Balancing the effects of 656 rearing at low temperature during early development on sex ratios, growth and maturation 657 in the European sea bass (Dicentrarchus labrax).: Limitations and opportunities for the 658 production of highly female-biased stocks. Aquaculture 296:347-358.

659 Navarro-Martín L., Viñas J., Ribas L., Díaz N., Gutiérrez A., Di Croce L., Piferrer F. 2011. DNA 660 Methylation of the Gonadal Aromatase (cyp19a) Promoter Is Involved in Temperature661 Dependent Sex Ratio Shifts in the European Sea Bass. PLoS genetics 7:e1002447.

662 Olson CE., Roberts SB. 2014. Genome-wide profiling of DNA methylation and gene 663 expression in Crassostrea gigas male gametes. Frontiers in physiology 5:224.

664 Olson CE., Roberts SB. 2015. Indication of family-specific DNA methylation patterns in 665 developing oysters. bioRxiv:012831. DOI: 10.1101/012831.

666 Ong-Abdullah M., Ordway JM., Jiang N., Ooi S-E., Kok S-Y., Sarpan N., Azimi N., Hashim AT., 667 Ishak Z., Rosli SK., Malike FA., Bakar NAA., Marjuni M., Abdullah N., Yaakub Z., Amiruddin 668 MD., Nookiah R., Singh R., Low E-TL., Chan K-L., Azizi N., Smith SW., Bacher B., Budiman MA., 669 Van Brunt A., Wischmeyer C., Beil M., Hogan M., Lakey N., Lim C-C., Arulandoo X., Wong C-K., 670 Choo C-N., Wong W-C., Kwan Y-Y., Sharifah Shahrul Rabiah., Sambanthamurthi R., 671 Martienssen RA. 2015. Loss of Karma transposon methylation underlies the mantled 672 somaclonal variant of oil palm. Nature 525:533-537.

673 Paneru B., Al-Tobasei R., Palti Y., Wiens GD., Salem M. 2016. Differential expression of long 674 non-coding RNAs in three genetic lines of rainbow trout in response to infection with 675 Flavobacterium psychrophilum. Scientific reports 6:36032.

676 Panserat S., Marandel L., Geurden I., Veron V., Dias K., Plagnes-Juan E., Pegourié G., Arbenoits 677 E., Santigosa E., Weber G., Verlhac Trichet V. 2017. Muscle catabolic capacities and global 678 hepatic epigenome are modified in juvenile rainbow trout fed different vitamin levels at first 679 feeding. Aquaculture 468, Part 1:515-523.

680 Parker LM., O’Connor WA., Raftos DA., Pörtner H-O., Ross PM. 2015. Persistence of Positive 681 Carryover Effects in the Oyster, Saccostrea glomerata, following Transgenerational Exposure 682 to Ocean Acidification. PloS one 10:e0132276. 
683 Parker LM., Ross PM., O’Connor WA., Borysko L., Raftos DA., Pörtner H-O. 2012. Adult

684 exposure influences offspring response to ocean acidification in oysters. Global change 685 biology 18:82-92.

686 Patel CJ., Chen R., Kodama K., Ioannidis JPA., Butte AJ. 2013. Systematic identification of 687 interaction effects between genome- and environment-wide associations in type 2 diabetes 688 mellitus. Human genetics 132:495-508.

689 Peschansky VJ., Wahlestedt C. 2014. Non-coding RNAs as direct and indirect modulators of 690 epigenetic regulation. Epigenetics: official journal of the DNA Methylation Society 9:3-12.

691 Potok ME., Nix DA., Parnell TJ., Cairns BR. 2013. Reprogramming the maternal zebrafish 692 genome after fertilization to match the paternal methylation pattern. Cell 153:759-772.

693 Rechavi O., Houri-Ze'evi L., Anava S., Goh WSS., Kerk SY., Hannon GJ., Hobert O. 2014.

694 Starvation-induced transgenerational inheritance of small RNAs in C. elegans. Cell 158:277695287.

696 Rey O., Danchin E., Mirouze M., Loot C., Blanchet S. 2016. Adaptation to Global Change: A 697 Transposable Element-Epigenetics Perspective. Trends in ecology \& evolution 31:514-526.

698 Rivera-Casas C., Gonzalez-Romero R., Garduño RA., Cheema MS., Ausio J., Eirin-Lopez JM. 699 2017. Molecular and Biochemical Methods Useful for the Epigenetic Characterization of 700 Chromatin-Associated Proteins in Bivalve Molluscs. Frontiers in physiology 8:490.

701 Riviere G., He Y., Tecchio S., Crowell E., Gras M., Sourdaine P., Guo X., Favrel P. 2017. Dynamics 702 of DNA methylomes underlie oyster development. PLoS genetics 13:e1006807.

703 Rodgers AB., Morgan CP., Leu NA., Bale TL. 2015. Transgenerational epigenetic 704 programming via sperm microRNA recapitulates effects of paternal stress. Proceedings of 705 the National Academy of Sciences 112:13699-13704.

706 Rondon R., Grunau C., Fallet M., Charlemagne N., Sussarellu R., Chaparro C., Montagnani C., 707 Mitta G., Bachère E., Akcha F., Cosseau C. 2017. Effects of a parental exposure to diuron on 708 Pacific oyster spat methylome. DOI: 10.1093/eep/dvx004. 
709 Rosani U., Pallavicini A., Venier P. 2016. The miRNA biogenesis in marine bivalves. PeerJ $710 \quad 4: \mathrm{e} 1763$.

711 Salinas S., Brown SC., Mangel M., Munch SB. 2013. Non-genetic inheritance and changing

712 environments. Non-Genetic Inheritance 1. DOI: 10.2478/ngi-2013-0005.

713 Sellos D. 1985. The histones isolated from the sperm of the oyster Crassostrea gigas. Cell 714 differentiation 17:183-192.

715 Shao C., Li Q., Chen S., Zhang P., Lian J., Hu Q., Sun B., Jin L., Liu S., Wang Z., Zhao H., Jin Z., 716 Liang Z., Li Y., Zheng Q., Zhang Y., Wang J., Zhang G. 2014. Epigenetic modification and 717 inheritance in sexual reversal of fish. Genome research 24:604-615.

718 Simmen MW., Leitgeb S., Charlton J., Jones SJ., Harris BR., Clark VH., Bird A. 1999.

719 Nonmethylated transposable elements and methylated genes in a chordate genome. Science $720 \quad 283: 1164-1167$.

721 Soubry A., Hoyo C., Jirtle RL., Murphy SK. 2014. A paternal environmental legacy: evidence 722 for epigenetic inheritance through the male germ line. BioEssays: news and reviews in 723 molecular, cellular and developmental biology 36:359-371.

724 Stewart S., Tsun Z-Y., Izpisua Belmonte JC. 2009. A histone demethylase is necessary for 725 regeneration in zebrafish. Proceedings of the National Academy of Sciences of the United 726 States of America 106:19889-19894.

727 Strömqvist M., Tooke N., Brunström B. 2010. DNA methylation levels in the 5' flanking 728 region of the vitellogenin I gene in liver and brain of adult zebrafish (Danio rerio)--sex and 729 tissue differences and effects of 17alpha-ethinylestradiol exposure. Aquatic toxicology $73098: 275-281$.

731 Talbert PB., Henikoff S. 2010. Histone variants--ancient wrap artists of the epigenome. 732 Nature reviews. Molecular cell biology 11:264-275.

733 Talbert PB., Henikoff S. 2014. Environmental responses mediated by histone variants. 734 Trends in cell biology 24:642-650. 
735 Terova G., Díaz N., Rimoldi S., Ceccotti C., Gliozheni E., Piferrer F. 2016. Effects of Sodium

736 Butyrate Treatment on Histone Modifications and the Expression of Genes Related to

737 Epigenetic Regulatory Mechanisms and Immune Response in European Sea Bass

738 (Dicentrarchus Labrax) Fed a Plant-Based Diet. PloS one 11:e0160332.

739 Tweedie S., Charlton J., Clark V., Bird A. 1997. Methylation of genomes and genes at the

740 invertebrate-vertebrate boundary. Molecular and cellular biology 17:1469-1475.

741 Utting SD., Millican PF. 1997. Techniques for the hatchery conditioning of bivalve

742 broodstocks and the subsequent effect on egg quality and larval viability. Aquaculture

743 155:45-54.

744 Valenzuela-Miranda D., Gallardo-Escárate C. 2016. Novel insights into the response of

745 Atlantic salmon (Salmo salar) to Piscirickettsia salmonis: Interplay of coding genes and

746 lncRNAs during bacterial infection. Fish $\mathcal{E}$ shellfish immunology 59:427-438.

747 Vastenhouw NL., Schier AF. 2012. Bivalent histone modifications in early embryogenesis.

748 Current opinion in cell biology 24:374-386.

749 Venney CJ., Johansson ML., Heath DD. 2016. Inbreeding effects on gene-specific DNA

750 methylation among tissues of Chinook salmon. Molecular ecology 25:4521-4533.

751 Wang KC., Chang HY. 2011. Molecular mechanisms of long noncoding RNAs. Mol Cell. 43(6):

752 904-914.

753 Wang Y., Wang C., Zhang J., Chen Y., Zuo Z. 2009. DNA hypomethylation induced by

754 tributyltin, triphenyltin, and a mixture of these in Sebastiscus marmoratus liver. Aquatic

755 toxicology 95:93-98.

756 Weaver ICG., Cervoni N., Champagne FA., D’Alessio AC., Sharma S., Seckl JR., Dymov S., Szyf

757 M., Meaney MJ. 2004. Epigenetic programming by maternal behavior. Nature neuroscience $758 \quad 7: 847-854$.

759 Wheeler BM., Heimberg AM., Moy VN., Sperling EA., Holstein TW., Heber S., Peterson KJ.

760 2009. The deep evolution of metazoan microRNAs. Evolution \& development 11:50-68. 
761 Wu N., Yue H-M., Chen B., Gui J-F. 2009. Histone H2A has a novel variant in fish oocytes.

762 Biology of reproduction 81:275-283.

763 Wu S-F., Zhang H., Cairns BR. 2011. Genes for embryo development are packaged in blocks 764 of multivalent chromatin in zebrafish sperm. Genome research 21:578-589.

765 Yu A., Lepère G., Jay F., Wang J., Bapaume L., Wang Y., Abraham A-L., Penterman J., Fischer 766 RL., Voinnet O., Navarro L. 2013. Dynamics and biological relevance of DNA demethylation 767 in Arabidopsis antibacterial defense. Proceedings of the National Academy of Sciences of the 768 United States of America 110:2389-2394.

769 Yu H., Zhao X., Li Q. 2016. Genome-wide identification and characterization of long 770 intergenic noncoding RNAs and their potential association with larval development in the 771 Pacific oyster. Scientific reports 6:20796.

772 Zemach A., McDaniel IE., Silva P., Zilberman D. 2010. Genome-wide evolutionary analysis of 773 eukaryotic DNA methylation. Science 328:916-919.

774 Zhang C., Hoshida Y., Sadler KC. 2016. Comparative Epigenomic Profiling of the DNA 775 Methylome in Mouse and Zebrafish Uncovers High Interspecies Divergence. Frontiers in 776 genetics $7: 110$.

777 Zhao L., Schöne BR., Mertz-Kraus R., Yang F. 2017. Sodium provides unique insights into 778 transgenerational effects of ocean acidification on bivalve shell formation. The Science of the 779 total environment 577:360-366.

780 Zhou H., Ma T-Y., Zhang R., Xu Q-Z., Shen F., Qin Y-J., Xu W., Wang Y., Li Y-J. 2016. Analysis of 781 Different Ploidy and Parent-Offspring Genomic DNA Methylation in the Loach Misgurnus 782 anguillicaudatus. International journal of molecular sciences 17. DOI: $78310.3390 /$ ijms 17081299.

\section{Tables and Figures}


786 Figure 1. Schematic diagram of the aquaculture life-cycle highlighting key areas

787 where epigenetics could be applied to improve productivity and efficiency: Epigenetic

788 selection (red text) could be used, alone or in combination with genetic selection, to identify

789 individuals with desired traits. Environmental manipulation (blue text) refers to generating

790 environmentally-driven phenotypes mediated through epigenetic mechanisms. Two life

791 stages which may be particularly sensitive to generating within- or between-generation

792 'epigenetic memories' are larvae and broodstock, respectively. 


\section{Figure 1}

Schematic diagram of the aquaculture life-cycle highlighting key areas where epigenetics could be applied to improve productivity and efficiency

Epigenetic selection (red text) could be used, alone or in combination with genetic selection, to identify individuals with desired traits. Environmental manipulation (blue text) refers to generating environmentally-driven phenotypes mediated through epigenetic mechanisms. Two life stages which may be particularly sensitive to generating within- or betweengeneration 'epigenetic memories' are larvae and broodstock, respectively.

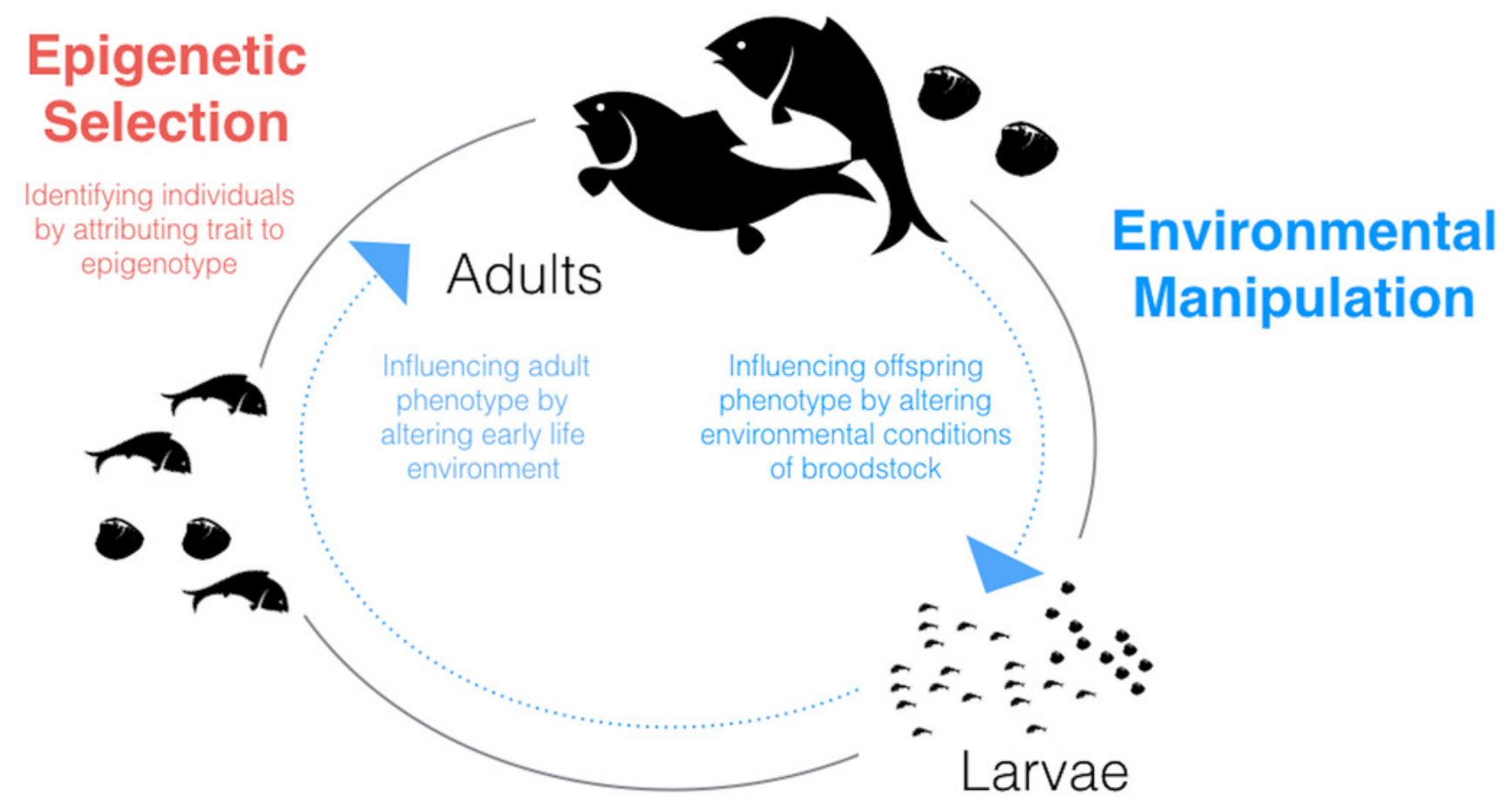

